\title{
Light verbs and the acquisition of finiteness and negation in Dutch as a second language ${ }^{1}$
}

Josje Verhagen

\section{Introduction}

Contrary to what has been observed for first language acquisition, the development of finiteness and negation in adult second language learners is a slow and gradual process that does not necessarily result in a stable target-like system. It is not unusual to find variability in the use of agreement marking and the placement of finite verbs, even in the speech of L2-learners who have reached a certain level of proficiency. ${ }^{2}$ To account for the complexity of the task in L2 acquisition, several explanations have been proposed that range from UG-based theories concerning the availability of functional categories (Herschensohn 2001; Prévost \& White 2000) to functional accounts that stress the importance of scope marking in L2 acquisition (Becker 2005; Jordens \& Dimroth 2006).

Despite these diverging explanations there is surprisingly little disagreement on the empirical data that describe learners' acquisition of finiteness marking and negation. Most researchers agree that light verbs such as copulae, modals, and auxiliaries are used in finite constructions earlier than lexical verbs. Parodi (2000) investigated data from Romance L2-learners of German and found that these learners used correct subject-verb agreement with auxiliaries, modals and the copula, while agreement marking on lexical verbs was absent or highly variable. Furthermore, Parodi looked at the position of the negator to find out whether verbs had been raised and found that learners consistently used post-verbal negation with light verbs, whereas they used pre-verbal negation with lexical verbs. Very similar results were obtained for L2 learners of other target languages (Giuliano 2003; Ionin \& Wexler 2002; Lardiere 1998 for L2 English and Meisel 1997; Giuliano \& Véronique 2005 for L2 French).

Although many researchers observed that light verbs become finite before lexical verbs in adult L2 acquisition, studies in which the precocious finite appearance of light verbs is in the focus of attention are scarce. This paper aims at filling part of this gap by presenting an experimental study on the precise role of light verbs, in particular of non-modal auxiliaries, in the acquisition of finiteness and negation. The organization of the paper is as follows: Section 1 presents earlier findings on finiteness and negation in L2 acquisition and considers how different theoretical approaches have dealt with these findings. Subsequently, Section 2 zooms in on the robust observation that light verbs appear as finite forms earlier than lexical verbs in L2 acquisition and addresses the question how this should be explained. In Section 3, the acquisition of finiteness and negation is described for L2 German, a language that is typologically very close to the target language under investigation: Dutch. Based on these data for L2 German, a number of research questions are formulated in Section 4.

\footnotetext{
${ }^{1}$ I would like to thank Christine Dimroth, Peter Jordens and Sarah Schimke for their helpful comments on earlier versions of this paper.

${ }^{2}$ The obligatory placement of the finite verb in V2 position in topicalized sentences, for instance, has been shown to remain problematic, even for advanced learners of Dutch and German (Dimroth et al. 2003, Becker 2005, Klein \& Perdue 1992).
} 
Section 5 briefly outlines the expression of finiteness and negation in Dutch. Subsequently, Section 6 describes the experimental tasks that were presented to the subjects and Section 7 provides the results. Finally, the findings are summarized and discussed in Section 8.

\section{Finiteness and negation in $\mathrm{L} 2$ acquisition}

\subsection{Form-oriented studies}

As early as in the 70s and 80s, the acquisition of negation constituted an important topic in studies on L2 acquisition (Cancino et al. 1978; Schumann 1979; Stauble 1984). The main outcome of these studies was that there appeared to be a fixed order of acquisition, irrespective of learner characteristics and language background. Consider the following developmental sequence, which was found by Cancino et al. (1978) for untutored learners of English:

1. no $+\mathrm{V} \quad$ 'I no see'

2. don't $+\mathrm{V} \quad$ 'He don't like it'

3. AUX + not 'Somebody is not coming in'/'I haven't seen all of it'

4. analyzed don't 'It doesn't spin'/'We didn't have a study period'

The examples show that the negator initially precedes lexical verbs (stage 1), while there is no such stage for auxiliaries: these verbs immediately occur with post-verbal negation (stage 3). Such differences in the placement of negation depending on whether the verb is an auxiliary or lexical verb were attested in almost all early negation studies, but no attempt was made at the time to explain the acquisition order in terms of finiteness of the verb. ${ }^{3}$

During the 90s, research on the acquisition of finiteness in L1 acquisition suggested that there was a strong contingency between agreement marking and verb placement (Clahsen \& Penke 1992; Poeppel \& Wexler 1993). More precisely, children consistently placed verbs that were finite before the negator, while they placed non-finite verbs behind the negator.

Departing from this finding in L1 acquisition as well as generative theory, researchers became occupied with the question of whether a similar relationship could be found for L2 acquisition. If so, this would suggest that L2 learners have still access to UG once they have already learnt a first language, in particular to functional categories such as INFL. In UG-terms, languages with verb-raising such as German and French have 'strong' verb features in INFL and since inflected verbs have to be checked against these features, they are raised to INFL. Thus, the finding that L2 learners raise finite verbs (to a position preceding negation) while they leave nonfinite verbs unraised (in a position following negation) implies that learners have access to the functional category INFL and its verb features, while a random positioning of finite and non-finite forms entails that access is 'impaired'.

The empirical evidence on this issue is far from conclusive, however. On the one hand, researchers found that there is no relation between agreement and negation placement in L2 acquisition. Meisel (1997) looked at L2 German and L2 French, for

\footnotetext{
3 An exception to this is Klein (1984), who reviews the early studies on negation and explains the attested patterns in terms of finiteness.
} 
example, and found that finite and non-finite verbs could both follow the negator. Therefore, he concluded that unlike in L1 acquisition, the development of negation (or verb-raising) in L2 acquisition is not related to agreement. Vainikka \& YoungScholten (1994) studied L2 data from German and made a similar observation: verbs could appear on either side of negation independently of whether they carried correct agreement marking. The authors proposed that learners do not have access to functional categories but only project lexical categories such as VP. Closely related ideas were formulated by Eubank $(1993 / 94,1996)$ and Beck (1998), who both assumed that functional categories transfer from the L1 into the L2 but crucially, the feature values associated with these categories do not transfer. Since these values are supposed to determine verb-raising the fact that features are neither strong nor weak results in non-finite verbs occupying both raised and unraised positions.

Opposed to the view that there is no relation between agreement marking and verb placement and hence that L2 learners do not have access to UG, scholars claimed that L2 learners have access to functional categories. Lardiere (1998) investigated data from a fossilized Chinese learner of English (a non-raising language) and found that agreement marking was virtually absent (apart from the copula and auxiliaries) and that verbs were not raised. She concluded that the learner had set the verb features to weak and therefore, did not raise the verb. Prévost \& White (2000) investigated data from L2 learners of French and German and found that these learners consistently raised finite verbs over negation while non-finite verbs occurred on either side of negation. To explain this differential behavior of finite and non-finite verbs, the authors proposed that finite forms are 'truly finite' whereas non-finite forms may occur as 'substitutes for finite forms'. This argument that has become known as the 'missing surface inflection hypothesis' holds that learners have sometimes problems accessing the correct morphological form. Rather than suffering from grammatical impairment, learners are sometimes unable to map abstract features to concrete morphological forms.

In sum, UG-oriented studies have mainly dealt with the accessibility of functional categories and their corresponding feature values. On the one hand, researchers found that the distribution of finite and non-finite with respect to negation is random in early L2 acquisition and therefore they concluded that functional categories are no longer available to the $\mathrm{L} 2$ learner. On the other hand, researchers agued that verbs preceding the negator are finite whereas verbs following the negator are not, leading to the conclusion that access to functional categories and features is intact. ${ }^{4}$ In the latter view, the incidental occurrence of non-finite verbs in raised position is assumed to be due to 'missing surface inflection', rather than grammatical impairment.

\subsection{Function-oriented studies}

Apart from studies that concentrate on the question of whether L2 learners have access to UG, a number of studies have appeared that look at the acquisition of finiteness and negation from a functional perspective (Becker 2005; Bernini 2003; Dimroth 2008; Giuliano 2003). The central idea in these studies is that negation bears scope and that it is scope relations that, together with the special semantic properties of light verbs, steer learners' acquisition of finiteness marking.

\footnotetext{
${ }^{4}$ It should be noted that, in fact, the variation is mainly due to non-finite verbs occurring on either side of negation, as finite verbs predominantly precede the negator.
} 
An important assumption in such studies is that verb morphology is not very informative at early stages of acquisition. Based on an analysis of L2 data from over 40 learners of different target languages, Klein \& Perdue (1997) showed that inflectional marking becomes functional only at later stages of development. Although even beginning learners sometimes use inflected forms, these forms do not bear any functional inflectional marking. The following illustrates this view (Klein \& Perdue 1997: 311):

'...lexical items typically occur in one invariant form. It corresponds to the stem, the infinitive or the nominative in the target language; but it can also be a form which would be an inflected form in the target language. Occasionally, a word shows up in more than one form, but this (rare) variation does not seem to have any functional value...'

Assuming that there is a stage in early L2 acquisition at which verbal morphology cannot inform us about the finiteness of the verb, the relative placement of verb and negator becomes the only diagnostic tool that can be used to determine whether verbs are finite or not. To avoid circularity but still enable investigations of finiteness and negation in L2 acquisition, an extra dimension has been added to the morphological and syntactic dimensions of finiteness. This extra dimension is a semantic one. Following Klein $(1994,1998)$, it has been assumed that finiteness is a carrier of two semantic features. First, it is a carrier of the topic time of the utterance: the time span about which the utterance makes a claim. Second, it carries the feature 'assertion' which means that it validates the state of affairs expressed in the utterance with respect to the topic. These two functions can best be illustrated with the following example from Klein (1994: 226)

\section{The book was on the table}

Klein argues that when contrastive stress is put on the copula, two contrasts are provoked, that illustrate the two semantic functions of finiteness. First, there is a tense contrast that becomes clear when the above sentence is opposed to 'The book IS on the table'. What is contrasted here is the time span about which the utterance makes a claim: the topic time. Second, a contrast regarding the claim becomes apparent when (1) is opposed to 'The book was NOT on the table'. Now, the assertion component is stressed, holding that the book's being on the table is true for a given topic time. Several researchers have shown that L2-learners express the semantic function of finiteness from the very onset of acquisition (Dimroth et al. 2003; Jordens \& Dimroth 2006), however, beginning learners do not yet use verbal morphology to do so.

Rather, they employ lexical devices such as adverbials and particles to mark the topic time and assert that a state of affairs is true of a given topic. At this early stage, the position of the negator (as well as other scope-bearing elements) is determined by a clear scope principle: the negator directly precedes the domain over which it has scope. Since the negator usually bears scope over a predicate and predicates often contain verbs, negation is typically pre-verbal at this stage. This can be illustrated with the following example, taken from Dimroth et al. (2003: 79):

$$
\text { Ik } \quad \text { hiet } \text { hapis }^{5} \text { gaan }
$$

\footnotetext{
${ }^{5}$ The word hapis is a case of transfer from Turkish hapishane 'prison'.
} 
Thus, unlike what we have seen in the previous section for UG-based theories, functionalist theories assume that morphosyntactic principles such as subject-verb agreement and raising do not yet determine word-order at the early stages. At the onset of acquisition, the presence of inflection does not imply the mastery of inflection and the placement of negation is determined by scope marking. Only later in the acquisition process do learners abandon these semantic-pragmatic principles in favor of subject-verb agreement and verb-raising. In Section 4, we will look in more detail at the development of finiteness and negation along these lines. Before we proceed to that section, however, let us take a closer look at the well-attested finding that light verbs appear as finite forms earlier than lexical verbs in L2 acquisition.

\section{Light verbs versus lexical verbs in $L 2$ acquisition}

Meisel (1983) already noted that, even at a stage where 'negator-verb' seems to be the dominant pattern, the negator tends to be placed to the right of modals, auxiliaries and the copula. Nevertheless, the precocious finite appearance of light verbs did not become an important topic of interest in the literature since the focus in most studies was on the morphosyntactic behavior of lexical verbs. ${ }^{6}$

An exception to this is Parodi $(1998,2000)$ who investigated the acquisition of subject-verb agreement and negation in longitudinal data from Romance learners of German, distinguishing between light verbs such as modals, auxiliaries, and possessive 'have', on the one hand, and lexical verbs, on the other. Her results indicated that agreement with lexical verbs showed a slow development towards the target system, while agreement with light verbs was sudden and correct. Regarding negation, Parodi observed that learners used post-verbal negation with light verbs, while post-verbal negation with lexical verbs was only used in cases of target-like subject-verb agreement. When agreement was not correct, pre-verbal negation turned out to be the dominant pattern. On the basis of these findings, Parodi concluded that there is a relation between morphology and syntax (negation) in L2 acquisition that becomes especially clear when one looks at light verbs and lexical verbs separately. Namely, at early stages of acquisition, there is a 'division of labor' between both verb classes: 'lexical verbs are responsible for lexical information, while light verbs are the main carriers of syntactical information' (Parodi 2000: 373).

In order to account for the different timing of light verbs and lexical verbs with respect to finiteness, Parodi proposed that light verbs spell out the functional category INFL, and specifically its AGR component. However, her account does not make clear why light verbs would do so in the first place and it also leaves implicit whether all light verbs are 'spell-outs of INFL' to the same extent or whether some verbs are better carriers of syntactic information than others.

A more comprehensive account of how light verbs and lexical verbs behave differently with respect to negation has been provided by Becker (2005) for L2 German. In the next section, a summary is given of the main findings of this study.

\footnotetext{
${ }^{6}$ This is not to say that no mention was made of the different behaviour of light verbs. For example, Clahsen (1988) noted that modals and auxiliaries regularly preceded the negator but took this as evidence against transfer, since post-verbal negation was not an option in the learners' native language.
} 


\section{Finiteness and negation in L2 German}

Becker (2005) studied the development of finiteness and negation in L2-learners of German with Italian as their L1. Becker distinguishes four stages but for the present purpose, the first two stages can be collapsed: (1) Pre-verbal negation with lexical verbs, (2) Post-verbal negation with auxiliaries, and (3) Post-verbal negation with lexical verbs.

At stage 1 the ordering of elements is determined by a pragmatic principle: the topic precedes the predicate. When utterances are negated, the negator is placed between topic and predicate since it has scope over the predicate:

$$
\begin{array}{llll}
\text { Mein } & \text { vater } & \text { nicht } & \text { schlafen } \\
\text { My } & \text { father not } & \text { sleep-inf }
\end{array}
$$

(Becker 2005: 287)

As can be seen in (3), lexical verbs do not yet show functional use of inflection and are positioned in the predicate part of the utterance. Since the negator precedes the predicate, negation is pre-verbal at this stage. However, in copula sentences the negator follows the copula verb:

$\begin{array}{llll}\text { Deutschland } & \text { is } & \text { nich patria } \\ \text { Germany } & \text { be } & \text { not } & \text { home country (Becker 2005: 288) }\end{array}$

Becker notes that the copula initially appears in affirmative contexts only such that there is a complementary distribution between copula sentences and sentences containing a negator. She argues therefore that the copula is an early assertion marker and not yet a marker of tense (there are no contrastive tense forms) at the current stage.

The second stage is characterized by the emergence of auxiliaries. As opposed to the earlier utterances that where unspecified for finiteness, the 'auxiliary-past participle' complex spells out the finite and non-finite part of a sentence: auxiliaries typically appear as morphologically finite forms, whereas past participles are overtly marked for non-finiteness by means of a ge-prefix. Due to their semantic 'emptiness' and topic time marking function, auxiliaries consistently precede the negator:

$$
\begin{aligned}
& \text { Er hat nicht die zug gesehen } \\
& \mathrm{He} \text { have-3sg not the train see-pp (Becker 2005: 293) }
\end{aligned}
$$

An important point to be stressed here is that auxiliaries change the organization of utterances at the surface level only. That is, the auxiliary construction still conforms to the information-structural principles of topic-focus that determined word order at the previous stage, even though it looks target-like. As such, auxiliary sentences have a clear advantage for L2 learners: they bring them closer to the utterance organization of the target-language, while at the same time, they allow them to keep the lexical (non-finite) information in topic and focus positions and the functional (finite) information in the middle, in between topic and focus.

The final stage involves a reorganization of the earlier structure, caused by the fact that auxiliaries lack a clear lexical meaning. Due to their semantic 'emptiness' and co-occurrence with non-finite forms (past participles), the formal properties of auxiliaries (i.e., subject-verb agreement) become visible to the learner. As put by Becker: 'morphological marking of finiteness first appears on auxiliaries in aux-V 
constructions, i.e., in cases where the separation between FIN and INF is transparent' (p. 293). Consequently, agreement marking is acquired and extended to lexical verbs. These verbs are then raised to a position higher up in the sentence. This is a complex step because the separation of functional and lexical information that characterized the previous stages can now no longer be maintained: the finite lexical verb expresses both lexical and functional information in one fused form that occurs in a finite position. In negated sentences, lexical verbs are raised over nicht, resulting in postverbal negation:

$$
\begin{array}{lllll}
\text { Er } & \text { arbeit } & \text { nicht } & \text { gut } & \\
\mathrm{He} & \text { work-0 } & \text { not } & \text { well } & \text { (Becker 2005: 298) }
\end{array}
$$

Unlike negation, which is now generally correct, agreement marking on lexical verbs remains variable for some time: '[T] here is an extended phase in which correct and incorrect [verb] forms coexist' (Becker 2005: 298).

In sum, the stage-model can best be characterized as a series of successive stages that are marked by the emergence of a certain verb or verb form. The various $\operatorname{verb}(\mathrm{s})$ (forms) appear at different points in time and serve different functions. The copula emerges first and marks assertion: initially, it does not yet express tense and it appears in complementary distribution with the negator. When the copula is used in negated sentences, it consistently precedes the negator. Somewhat later, auxiliaries are added to the system and these light verbs enable the learner to stick to an information structure-based word order, while at the same time allowing a structure that comes close to that of the target language. Auxiliaries lead to the acquisition of subject-verb agreement. The final step involves the extension of agreement marking to lexical verbs and the raising of such verbs over negation to a finite position.

When we compare the stage-model with the UG-based approaches to finiteness that were discussed in the previous section, it seems that the model can best be subsumed under the view that syntax develops dependently on morphology.

Namely, Becker assumes that the acquisition of agreement marking on lexical verbs entails verb-raising of such verbs. At the same time, however, early light verbs such as the copula are considered carriers of the finiteness features assertion and/or tense. It is only after the acquisition of auxiliaries that all functions of finiteness become fused within one verb form and learners organize their utterances according to morphosyntactic principles, rather than information-structural ones. In this sense, the stage model is radically different from UG-based theories that assume that functional categories determine utterance organization from the earliest stages onwards.

\section{Research questions}

The main purpose of this study is to investigate the role of light verbs, in particular of auxiliaries, in the acquisition of finiteness and negation in L2 Dutch. Based on earlier findings, it can be hypothesized that L2 learners of Dutch place the negator behind light verbs such as the copula, modal verbs and auxiliaries before they do so with lexical verbs. Therefore, the first research question of the study is the following:

1. Do learners produce post-verbal negation with light verbs before they do so with lexical verbs? 
If this is true, the question arises when learners produce post-verbal negation with lexical verbs as well. Becker argued for L2 German that post-verbal negation with lexical verbs is only attested after the acquisition of auxiliaries. Based on this, the following question can be formulated for L2 Dutch:

2. Do learners only produce post-verbal negation with lexical verbs after they have acquired auxiliaries?

The prediction here is that that learners who do not use auxiliaries never produce postverbal negation with lexical verbs, whereas learners who produce auxiliaries do place the negator post-verbally with such verbs. Crucially, the idea that there is a relation between the acquisition of auxiliaries and post-verbal negation (verb-raising) hinged on the assumption that auxiliaries entail the acquisition of subject-verb agreement. Auxiliaries co-occur with verb forms that are clearly non-finite (past participles) and therefore, the finite/non-finite distinction becomes clear to the learner. Furthermore, the fact that auxiliaries lack a clear lexical content makes the leaner aware of subjectverb agreement on such verbs. Along these lines, post-verbal negation could be considered a by-product of the acquisition of agreement marking since, as soon as learners start to inflect verbs, they are expected to raise these verbs over negation. Unfortunately, Becker does not provide information about agreement marking in her data. However, the assumption that verb-raising is dependent on subject-verb agreement is an important one that has received enormous attention in the literature (see Section 1.1). Therefore, the two final questions address the possible relation between agreement and verb-raising (negation) in L2 Dutch:

3. Do learners acquire subject-verb agreement only after they have acquired auxiliaries?

4. Do learners more often mark subject-verb agreement on raised verbs than on verbs that are not raised?

The prediction for question 3 is that learners who have acquired auxiliaries more accurately mark subject-verb agreement on lexical verbs than learners who have not acquired auxiliaries. ${ }^{7}$ Regarding question 4 , the assumption is that learners produce correct agreement on verbs that occur with post-verbal negation (raised verbs) but not - or less so - on verbs that occur with pre-verbal negation (non-raised verbs).

As we saw above, studies have provided mixed results regarding the last question. While some studies pointed to a clear correlation between raising and agreement, with possible overgeneralizations of non-finite forms in raising contexts ('missing surface inflection'), others showed no correlation at all. Since no systematic studies on Dutch have been conducted thus far, it is interesting to see what patterns are found for this language. Evidence that the negator follows finite verbs in the data of learners who have acquired auxiliaries, but precedes non-finite verbs in the data of learners who have not yet done so, would moreover support the idea of the acquisition of auxiliaries as an important step towards finiteness.

\footnotetext{
${ }^{7}$ A problem with this idea is that learners usually become more accurate over time in several domains. Consequently, in case a correlation is found between auxiliary acquisition, on the one hand, and verbraising or agreement marking, on the other, it is hard to disentangle whether this correlation is indeed a causal relationship or whether both the acquisition of auxiliaries and verb-raising/agreement are due to a higher overall proficiency in the L2.
} 


\section{Finiteness, negation and light verbs in Dutch}

This section outlines the expression of (sentence) negation ${ }^{8}$, subject-verb agreement and the use of light verbs in Dutch. Only declarative main clauses in the present tense will be considered. ${ }^{9}$

\subsection{Negation}

Dutch is a V2 language, which means that in declarative main clauses the finite verb occurs in second position. In such clauses the negator niet precedes the non-finite verb. This is illustrated in example (7):

$$
\begin{array}{llll}
\text { Peter } & \text { heeft } & \text { niet } & \text { gelopen } \\
\text { Peter have-3sg } & \text { not } & \text { walk-pp }
\end{array}
$$

When the sentence does not contain a modal verb or an auxiliary, the lexical verb is raised to the V2 position, leaving the negator behind. This results in constructions of the type in (8).

$$
\begin{array}{lll}
\text { Peter loopt } & \text { niet } \\
\text { Peter } & \text { walk-3sg } & \text { not }
\end{array}
$$

\subsection{Subject-verb agreement}

Verbal suffixes mark person and number of the grammatical subject in Dutch. Table 1 lists the forms for the present tense as well as the infinitive and past participle for the verb werken 'work'.

Table 1. Agreement paradigm for the Dutch verb werken 'to work'

\begin{tabular}{lll}
\hline & Non-finite & Finite (present) \\
\hline Infinitive & werk -en & \\
Past participle & ge- werk $-\mathrm{t}$ & \\
$1 \mathrm{sg}$ & & werk - \\
$2 \mathrm{sg} / 3 \mathrm{sg}$ & & werk -t \\
$1 \mathrm{pl} / 2 \mathrm{pl} / 3 \mathrm{pl}$ & & werk -en \\
\hline
\end{tabular}

\subsection{Light verbs}

Dutch has a number of light verbs. First, there is an obligatory copula zijn 'be' that expresses a state or property. ${ }^{10}$

\footnotetext{
${ }^{8}$ Sentence negation differs from constituent negation, which has 'narrow scope' in that only affects one constituent.

${ }^{9}$ In Dutch subordinate clauses, the finite verb is placed in final position. Negation precedes the finite verb in such clauses, e.g., Ik heb gezien dat hij niet heeft gewerkt 'I have seen that he not has worked'. ${ }^{10}$ Apart from this copula, there is a copula worden 'become' that denotes a change of state (e.g. hij wordt oud 'he becomes old'). Since the learners in the present study did not use this copula, it will not be further discussed.
} 


$$
\begin{array}{lll}
H i j & \text { is } & \text { aardig } \\
\mathrm{He} & \text { be-3sg } & \text { nice }
\end{array}
$$

There is also a series of modal verbs expressing, among others, volition, obligation, and permission. These modal verbs combine with infinitives that are placed sentencefinally, as shown in the following example that contains a form of willen 'want':

$$
\begin{array}{lllll}
\text { Hij } & \text { wil } & \text { vandaag } & \text { een film } & \text { zien } \\
\mathrm{He} & \text { want-0 } & \text { today } & \text { a movie } & \text { watch-inf }
\end{array}
$$

Moreover, there is a light verb gaan 'go' that is commonly used to mark (near) future and, like modal verbs, occurs in periphrastic constructions with the infinitive ${ }^{12}$ :

$\begin{array}{lll}\text { Hij } & \text { gaat } & \text { boodschappen doen } \\ \mathrm{He} & \text { go-3sg } & \text { shopping do-inf }\end{array}$

Finally, Dutch has two auxiliary verbs that co-occur with past participles and mark perfective aspect: hebben 'have' and zijn 'be'. Of these forms, hebben is by far most frequent, since zijn is only used with unaccusative and ergative verbs.

$\begin{array}{lllll}\mathrm{Hij} & \begin{array}{l}\text { heeft } \\ \mathrm{He}\end{array} & \begin{array}{l}\text { vandaag } \\ \text { have-3sg }\end{array} & \begin{array}{l}\text { een film } \\ \text { a movie }\end{array} & \begin{array}{l}\text { gezien } \\ \text { watch-pp }\end{array} \\ \mathrm{Hij} & \text { is } & \text { gisteren } & \text { thuis } & \text { gekomen } \\ \mathrm{He} & \text { be-3sg } & \text { yesterday } & \text { home } & \text { come-pp }\end{array}$

\section{The study}

\subsection{Participants}

57 Moroccan learners and 46 Turkish learners of Dutch participated in the study. All subjects were recruited at schools where they took language courses that are obligatory for new immigrants in the Netherlands. They were at a beginner level ${ }^{13}$ and had been categorized as 'slow' learners in a special assessment procedure. ${ }^{14}$ The average length of residence in the Netherlands by the time of the experiment was 3:5 years for the Moroccan and 5:2 for the Turkish learners. Apart from these learners, 10 native speakers of Dutch participated in the study. The main purpose of including these subjects was to test whether the tasks actually elicited the intended (auxiliary) constructions from native speakers.

\footnotetext{
${ }^{11}$ As can be seen in this example, modal verbs are not marked for 3rd person singular.

${ }^{12}$ The verb zullen 'shall/will' is also used to mark future tense, but this verb is mainly used in contexts where it has a strong modal meaning (i.e., that of a promise) and is much less frequent than gaan.

${ }^{13}$ This level roughly corresponded to the A2/B1 level of the Common European Framework of Reference (Council of Europe 2001).

${ }^{14}$ In this procedure, a prediction was made about the amount of time learners would need to reach a certain level in the L 2 on the basis of their educational background and knowledge of other languages. The current subjects had only been at primary school or passed a few years at secondary school and in general they did not have extensive knowledge of other languages (except for some basic knowledge of French in the case of the Moroccan learners)
} 
The tasks that were used involved two film-retelling tasks and two picture stories. The first film-retelling task was a 10-minute film fragment from Charlie Chaplin's Modern Times. This fragment was chosen because it provided some good contexts for the use of auxiliaries. One of the scenes, for example, showed a woman who talked about a previous scene in which a girl had stolen a loaf of bread. For Dutch native speakers, it is natural to describe this scene by making use of an auxiliary, as in Zij heeft het brood gestolen 'She has stolen the loaf of bread'. In fact, the control data showed that all native speakers produced forms of hebben in their retellings at this point. The second film-retelling task involved a video that had been designed to elicit scope particles and negation in learner language (The finite story, Dimroth 2005).

Apart from these film-retelling tasks, two picture stories were administered to the participants. These consisted of a series of pictures that together formed a simple story, of which the main aim was to elicit the auxiliary hebben (see Appendix A). The control data indicated that all native speakers used at least one form of hebben in their story tellings.

The procedure for both tasks was the same: the experimenter and the participant together watched a film fragment (or picture in the case of the picture stories) and subsequently, the participant retold what had happened in the fragment. ${ }^{15}$

\subsection{Analyses}

After all recordings had been digitized, the data were transcribed and coded for type of verb (auxiliary, lexical verb etc.) and agreement marking using CLAN. ${ }^{16}$ In the remainder of the paper, verbs ending in -en will be glossed '-inf'. However, the reader should keep in mind that this form is homophonous with the plural ending in Dutch. Likewise, verbs ending in a null morpheme will be glossed ' -0 ' although this form is also used for $1 \mathrm{sg}$ (see Section 3). For an illustration, consider the following example:

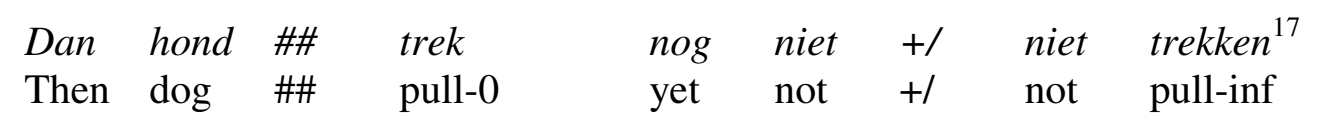

\section{Results}

\subsection{Results for negation}

The first two research questions of Section 4 concerned the acquisition of negation and the possible link between auxiliaries and negation in L2 acquisition. These questions are here repeated as 1' and 2':

1'. Do learners produce post-verbal negation with light verbs before they do so with lexical verbs?

\footnotetext{
${ }^{15}$ In between the production tasks, the subjects performed a number of comprehension tasks that will not be described in the present paper.

${ }^{16}$ See MacWhinney (1991).

${ }^{17} \mathrm{The}+$ / symbol in the glosses indicates a new start and a \# signals a short pause.
} 
2'. Do learners only produce post-verbal negation with lexical verbs after they have acquired auxiliaries?

All utterances containing niet and a verb were extracted from the data. This yielded a total of 492 and 485 negated utterances for the Moroccan and the Turkish learners respectively. Table 2 presents how often the negator occurred in pre- and post-verbal position with respect to the different verb types. Note that a distinction is made between 'light verbs', 'auxiliaries', and 'lexical verbs'. That is, here the category termed 'light verbs' does not include auxiliaries since these will be considered independently. It only contains the copula, modal verbs, gaan, and the verb form is that is further described below.

Table 2. Post- and pre-verbal negation with light verbs, auxiliaries, and lexical verbs

\begin{tabular}{lllll}
\hline & \multicolumn{2}{l}{ Moroccan learners } & \multicolumn{2}{l}{ Turkish learners } \\
\hline & V - NEG & $*$ NEG - V & V - NEG & *NEG - V \\
\hline Light verbs (no aux.) & 192 & 6 & 88 & 7 \\
Auxiliaries & 25 & 0 & 22 & 0 \\
Lexical verbs & 146 & 123 & 77 & 291 \\
\hline
\end{tabular}

The data show that negation nearly always follows light verbs: there are some instances of pre-verbal negation but the negator predominantly occurs post-verbally in the data of both the Moroccan and the Turkish learners. With the auxiliary hebben, negation is consistently post-verbal. Finally, negation with lexical verbs shows a mixed pattern: 123 out of all 269 negations are pre-verbal in the data of the Moroccan learners and the same holds for 291 out of 368 negations in the data of the Turks. Thus far, the results are thus in line with earlier findings in the literature.

A closer look at the data reveals that the different light verbs are acquired in a fixed order. More precisely, the following implicational scale could be defined:

$$
\text { copula }>\text { modals/gaan }>\text { is }>\text { auxiliaries }
$$

The copula appears to be acquired first, followed by modal verbs, the verb form is that co-occurs with lexical verbs and finally, auxiliaries. Evidence for this scale comes from the finding that all learners who used modal verbs also used the copula, but not vice versa. Likewise, all learners who produced auxiliaries produced all other light verbs whereas the reverse did not hold: not all learners who produced modal verbs also produced is and auxiliaries. For modals and gaan, it could not be determined which light verb was acquired first, as some learners produced either one of these verbs and others produced both.

Most importantly, however, the data show that the auxiliary hebben is acquired last. Since we are interested in what happens when auxiliaries are acquired, let us compare the data of the learners who did not produce auxiliaries and those who did. First, Table 3 presents how often negation was pre- and post-verbal with respect to the different verb types in the data of the learners who did not produce hebben. From now on, we will term these learners -AUX group.

Table 3. Post- and pre-verbal negation with different verb types for the -AUX group 


\begin{tabular}{lllll}
\hline & V - NEG & *NEG - V & V - NEG & *NEG - V \\
Copula & 13 & 0 & 8 & 0 \\
Modals/gaan & 43 & 3 & 8 & 5 \\
is & 30 & 3 & 16 & 2 \\
Lexical verbs & 8 & 85 & 6 & 170 \\
\hline
\end{tabular}

The data show that negation with the copula is always post-verbal. Moreover, the results indicated that the copula was often left out in negated utterances. This is in line with what was found for L2 German and suggests that the copula may function as an early assertion marker. The following utterance illustrates this pattern of complementary distribution of the copula and the negator. It was used to express that one of the protagonists of the finite story task should not be afraid of jumping out of the house but rather of the fire in his room.

$$
\begin{array}{llll}
\text { De bang } & \text { niet } & \text { daar, } & \text { is daar } \\
\text { The scared (=danger) not } & \text { there, } & \text { be-3sg there }
\end{array}
$$

As for modal verbs, the data in Table 3 show that the negator predominantly occurs in post-verbal position but incidentally also precedes the modal. ${ }^{18}$ The below utterances, that were produced by the same learner, illustrate these two patterns:

$\begin{array}{llllll}\begin{array}{l}\text { Meneer } \\ \text { Mister }\end{array} & \begin{array}{l}\text { rood } \\ \text { red }\end{array} & \begin{array}{l}\text { ook } \\ \text { also }\end{array} & \begin{array}{l}\text { wil } \\ \text { want }\end{array} & \begin{array}{l}\text { niet } \\ \text { not jump-inf }\end{array} \\ \text { Groene } & \text { man } & \text { niet } & \text { wil } & \text { springen } \\ \text { Green } & \text { man } & \text { not } & \text { want } & \text { jump-inf }\end{array}$

Apart from modal verbs, the verb gaan 'go' was also produced. Interestingly, the

Moroccan learners produced this verb much more often than the Turkish learners: 210 versus 25 instances, respectively. As with modal verbs, the negator followed gaan in the vast majority of cases:
De man
gaat
niet pakken
telefoon
The man
go-3sg
not take-inf
telephone

The light verb that appeared to be acquired after the copula and modals/gaan is a form of 'be' and has been reported on in earlier studies on L2 acquisition (Haberzettl 2003; Starren 2001; Van der Craats to appear). For an illustration of this light verb, consider the utterances in (19) and (20):

$$
\begin{array}{lll}
H i j & \text { is } & \text { slapen } \\
\mathrm{He} & \text { is } & \text { sleep-inf }
\end{array}
$$

$\begin{array}{lllll}\text { Charlie chaplin } & \text { is } & \text { steel } & \text { de } & \text { brood } \\ \text { Charlie chaplin } & \text { is } & \text { steal-0 } & \text { the } & \text { bread }\end{array}$

\footnotetext{
${ }^{18}$ Sentences that contained a modal verb but no lexical verb, such as Dat kan niet 'That can not' (lit. That is not possible), are not included in this table.
} 
In the literature, the question of how this structure should be interpreted has led to different proposals. Starren (2001) looked at data from Turkish and Moroccan learners of Dutch and suggested that is marks perfective or durative aspect. However, Van der Craats (to appear) concluded that is does not carry a temporal meaning in the data from Turkish learners of Dutch but rather, constitutes a structural device that helps these learners acquiring finite syntax. For reasons of space, the possible function of the construction will not be further discussed in the present paper. However, one remark seems noteworthy, that is, it seems safe to assume here that the form is is not yet an instantiation of the aspectual auxiliary zijn that marks perfective aspect with unaccusatives and ergative verbs in the target language. First, there are many occurrences where a perfective reading does not seem plausible. ${ }^{19}$ Moreover, is was frequently produced by learners, who did not yet use hebben, but much less so by learners who produced hebben. This suggests that is and hebben do not constitute cases of the same type of auxiliary, at least not at the current stage of development. ${ }^{20}$

When $i$ s-constructions are negated, the negator nearly always appears in postverbal position. Sometimes however, negation also preceded the verb form is. ${ }^{21}$ Consider (21) and (22) for examples:

$\begin{array}{llllll}\begin{array}{l}\text { Een } \\ \text { A }\end{array} & \begin{array}{l}\text { meisje } \\ \text { girl is }\end{array} & \begin{array}{l}\text { niet } \\ \text { not }\end{array} & \begin{array}{l}\text { krijgen } \\ \text { get-inf }\end{array} & \begin{array}{l}\text { een } \\ \text { a }\end{array} & \begin{array}{l}\text { brood } \\ \text { loaf of bread }\end{array} \\ \text { Die } & \text { man niet } & \text { is } & \text { stolen maar } & \text { die vrouwtje } \\ \text { That man not } & \text { is } & \text { steal-11 } & \text { but } & \text { that woman-dim }\end{array}$

Considering negation with lexical verbs, it appears that negation is most often preverbal. In the data of the Moroccan learners, niet appears post-verbally in only 8 out of all 93 negations and for the Turkish learners, even fewer post-verbal negations are found: 6 out of 176. Hence, pre-verbal negation is clearly the dominant pattern. Moreover, a close look at the few instances of post-verbal negation that are found reveals that learners may not have used these productively. In (23), for example, the negator has narrow scope over boven 'up', instead of over the entire sentence.

Interestingly moreover, the learner who produces this utterance uses the pre-verbal construction in (24) to refer to the exact same scene a few utterances later.

$\begin{array}{ll}\text { Maar hij kijkt } & \text { niet boven, alleen achter } \\ \text { But he look-3sg not up, only behind } & \\ \text { Niet kijken } & \text { boven } \\ \text { Not look-inf } & \text { up }\end{array}$

\footnotetext{
${ }^{19}$ Consider, for example, the following utterance in which the experimenter asks the learner to tell what happened in a film fragment and the learner verifies whether she has understood this right by using is:

Kan je vertellen wat er is gebeurd? Is praten?

Can you tell what happened? Is talk-inf?

${ }^{20}$ Evidently, when they come closer to the target language system learners start using forms of 'be' in auxiliary constructions.

${ }^{21}$ The ordering in (36) might be a case of narrow scope: according to this idea, 'niet' would have narrow scope over 'niet stolen' and mark a contrast with the woman that has stolen in the following way: die man niet [is stolen] maar die vrouwtje [is stolen] 'the man not [is stolen] maar die vrouwtje [is stolen].

${ }^{22}$ The gloss 'll' means 'learner language' and refers to a form that does not occur in the target language.
} 
While some post-verbal negations looked target-like, the total number of post-verbal negations in the -AUX group makes up only a very small proportion of all negations (only 3\%). Therefore, it can be safely concluded that post-verbal negation is not yet productive for the learners in this group.

Now let us consider the data of the learners who did produce auxiliaries, the so-called +AUX group, and see whether these learners' use of negation differs from that of the -AUX group. ${ }^{23}$ Table 4 presents how often negation was pre- and post-verbal with the different verb types that were produced by the +AUX group.

Table 4. Post- and pre-verbal negation with different verb types for the + AUX group

\begin{tabular}{|l|l|l|l|l|}
\hline & \multicolumn{2}{|l|}{ Moroccan learners } & Turkish learners \\
\hline & verb-NEG & $*$ NEG-verb & Verb-NEG & $*$ NEG-verb \\
\hline Copula & 31 & 0 & 14 & 0 \\
\hline Modals/gaan & 69 & 0 & 22 & 0 \\
\hline is & 6 & 0 & 20 & 0 \\
\hline Auxiliaries & 25 & 0 & 22 & 0 \\
\hline Lexical verbs & 138 & 38 & 71 & 121 \\
\hline
\end{tabular}

When we look at these data, two clear differences with the data of the -AUX group can be observed. First, negation with light verbs is now always post-verbal. Second, and in line with the hypothesis, learners quite often produce post-verbal negation with lexical verbs, too. In the data of the Moroccan learners, 138 out of 176 negations have post-verbal negation, which amounts to $78 \%$ of all negations. For the Turkish learners, the proportion of post-verbal negations is somewhat lower: 71 out of 192 negations (37\%). Post-verbal negation has thus become the dominant pattern for the Moroccan learners, while for the Turkish learners, it has clearly increased, albeit not exceeded the number of pre-verbal negations. The utterances in (25) from a Turkish learner illustrate that pre- and post-verbal negation may alternate, even in very short stretches of discourse:

De groene meneer niet horen

Blauwe meneer ook komt rode meneer

Rode meneer ook slapen

Hij slapen maar horen niet
The green man not hear-inf Blue man also comes red man Red man also sleep He sleep but hear-inf not

On the basis of the data presented, the research questions that were formulated at the beginning of the section can be answered. Concerning the first question, the prediction is borne out that light verbs appear with post-verbal negation from the beginning, whereas lexical verb are initially used with pre-verbal negation. While the negator was incidentally found in pre-verbal position in sentences with modal verbs and with $i s$, post-verbal negation was clearly the dominant pattern. Furthermore, a positive answer can be given to the second question: the data showed that, with very few exceptions, only those learners who used hebben productively produced post-

\footnotetext{
${ }^{23}$ Auxiliary forms in the construction Ik heb vergeten 'I have forgotten' were not counted, as this construction is likely to be rote-learnt.
} 
verbal negation with lexical verbs. In the next section, it will be investigated whether the use of subject-verb agreement is also related to the production of hebben.

\subsection{Results for subject-verb agreement}

The following research questions were formulated concerning the acquisition of subject-verb agreement:

3'. Do learners acquire subject-verb agreement only after they have acquired auxiliaries?

4'. Do learners more often mark subject-verb agreement on verbs that are raised over negation than on verbs that are not raised?

Now that we have seen evidence that the use of post-verbal negation correlates with the acquisition of auxiliaries it becomes interesting to test the claim that auxiliaries lead to the acquisition of subject-verb agreement, and in turn, to verb-raising. Thus, two predictions have to be tested. First, does the +AUX group more correctly mark subject-verb agreement than the -AUX group? Second, do learners mark subject-verb agreement more often on raised verbs than on verbs that are not raised? In the below subsections, these two questions are dealt with in turn.

\subsubsection{Subject-verb agreement on lexical verbs}

Table 5 presents absolute and relative frequencies of correct agreement marking for the learners that did not produce auxiliaries, the -AUX group and the learners that did do so, the +AUX group. For this analysis, only lexical verbs were analyzed. ${ }^{24}$

Table 5. Agreement marking on lexical verbs for $-A U X$ and $+A U X$ group

\begin{tabular}{|l|cc|lc|}
\hline & \multicolumn{2}{|c|}{ Moroccan learners. } & \multicolumn{2}{|c|}{ Turkish learners } \\
\hline -AUX group & $56 \%$ & $(879 / 1569)$ & $38 \%$ & $(392 / 1031)$ \\
\hline +AUX group & $70 \%$ & $(1341 / 1916)$ & $53 \%$ & $(682 / 1287)$ \\
\hline
\end{tabular}

Clearly, the -AUX group produces less correct agreement marking than the +AUX group and this holds for both the Moroccan and the Turkish learners. The Moroccan learners in the -AUX group only mark $56 \%$ of all lexical verbs with the correct suffix, while the Moroccan learners in the +AUX group do so in $70 \%$ of all cases. A Pearson's Chi-square test shows that this difference is highly significant: $\chi^{2}(1)=$ 72.771, p<.000. Similarly, the Turkish learners who have acquired hebben significantly more often mark agreement on lexical verbs than the Turkish learners who have not yet acquired hebben: $\chi^{2}(1)=51.591, \mathrm{p}<.000$.

\subsubsection{Agreement in negated utterances}

Let us now take a closer look at negated contexts to see whether there is a difference in agreement marking between lexical verbs that are raised over the negator and those that are not. Table 6 presents for the $-\mathrm{AUX}$ and +AUX group how often verb

\footnotetext{
${ }^{24}$ Only verbs that occurred with an overt subject were taken into account for this analysis.
} 
agreement was marked on verbs that were raised over negation (verb-NEG) and verbs that were not raised (*NEG-verb).

Table 6. Agreement marking in negated utterances for -AUX and +AUX group

\begin{tabular}{|c|c|c|c|c|}
\hline & \multicolumn{2}{|c|}{ Moroccan learners. } & \multicolumn{2}{|c|}{ Turkish learners } \\
\hline & verb-NEG & *NEG-verb & verb-NEG & *NEG-verb \\
\hline -AUX group & $50 \% \quad(4 / 8)$ & $4 \% \quad(3 / 85)$ & $33 \% \quad(2 / 6)$ & $8 \% \quad(14 / 170)$ \\
\hline+ AUX group & $86 \%(118 / 138)$ & $18 \% \quad(7 / 38)$ & $(47 / 71)$ & $(8 / 121)$ \\
\hline
\end{tabular}

When we look at the data of the -AUX group and leave aside the low absolute frequencies for post-verbal negation, it appears that very few verbs occurring with pre-verbal negation bear correct agreement: $4 \%$ and $8 \%$ for the Moroccan and Turkish learners in this group respectively. A chi-square shows that the differences for the Moroccan learners in the -AUX group are significant: $\chi^{2}(1)=22.686, p=.001$. This indicates that these learners mark agreement significantly more often on raised verbs than on verbs that are not raised. For the Turkish learners, a Fisher's exact test was performed due to low numbers and this turned out not be significant $(\mathrm{p}=.083)$, but this is probably due to the low values. The data from the +AUX group show a clear contingency pattern, however: verbs that are raised over negation much more often correctly agree with the subject than verbs that are not raised. For both language groups, clear effects were obtained: $\chi^{2}(1)=65.157, \mathrm{p}<.000$ for the Moroccan learners and $\chi^{2}(1)=77.722, p<.000$ for the Turkish learners.

In short, it can therefore be concluded that there is a correlation between the position of the verb with respect to negation, on the one hand, and the presence of correct agreement, on the other. This can be nicely illustrated with the following excerpt from a film retelling from a Turkish learner, who uses the same verb with different verbal markings, depending on whether the verb is raised or not:

Charlie chaplin gaat naar cafeteria
dan \#\#\# hij koopt eten $+/$ pakt eten
dan veel eten
maar hij betaalt niet he?
betaalt niet
en hij roept de politie
zegt 'ik betaal niet'
dan hij geeft chocolade tegen kinderen
maar nog niet betalen ofzo

Charlie chaplin goes to cafetaria then he buys food $+/$ takes food then much eat (or: food) but he pay-3sg not right? pay-3sg not and he calls the police says 'I pay-0 not' then he gives chocolate to children but still not pay-inf or so

\section{Conclusion and discussion}

This study shows that Moroccan and Turkish L2 learners of Dutch acquire finiteness and negation in a systematic way. It supports earlier findings that light verbs appear with post-verbal negation earlier than lexical verbs. Importantly however, the data also indicate that one should not only distinguish between light verbs and lexical verbs when studying learners' acquisition of finiteness, but that it is warranted to split up the class of light verbs: these verbs show up at different stages of acquisition and behave differently with respect to finiteness. While negation is sometimes pre-verbal 
with modal verbs and gaan, it is consistently post-verbal with the copula and the auxiliary hebben.

This finding is important as it provides evidence for the role of scope in learner language. More precisely, it supports the idea that scope marking determines negation placement during early stages of acquisition: the copula and hebben have less semantic content than modal verbs and gaan and therefore more clearly fall outside the scope of the negator. In particular, modal verbs are not as poor in lexical content as auxiliary verbs and the copula. This also becomes apparent from the fact that they can occur in isolation in Dutch, that is, without a lexical verb (e.g., Dat kan 'That can', meaning 'That is possible').

Most importantly, however, the study corroborates the earlier finding for L2 German that auxiliaries are of crucial importance in the acquisition of finiteness and negation: it is only after the acquisition of these light verbs that learners produce postverbal negation with lexical verbs. Similar observations have been made for L1 Dutch (Jordens 2002). The present data suggest that this is due to the acquisition of subjectverb agreement, that is first instantiated on auxiliaries and later also on lexical verbs. Learners significantly more often marked agreement on verbs that were raised over negation than on verbs that were not raised. Hence, the findings provide evidence that subject-verb agreement on lexical verbs leads to the acquisition of verb-raising.

Interestingly, the Moroccan and Turkish learners acquired finiteness and negation in a remarkably similar way, despite the fact that there are some fundamental typological differences between their native languages. First, Moroccan Arabic makes use of light verbs, whereas Turkish does not. Second, verbs raise in Moroccan Arabic but not in Turkish, that is, they consistently occur in sentence-final position in this language. It is interesting, then, that the Moroccan and Turkish learners in the current study showed a similar development. They did not only acquire the different Dutch light verbs in the same order, but also first produced pre-verbal negation with lexical verbs and only acquired finiteness marking after the acquisition of hebben. This suggests that the acquisition of finiteness and negation may follow universal tendencies.

Nevertheless, some (minor) differences between Moroccan and Turkish learners were also observed. One clear difference was that the Moroccan learners made more frequent use of light verbs, in particular of gaan, than the Turkish learners. As for gaan, Van der Craats (to appear) suggests that this is due to direct transfer from the Moroccan light verb $\dot{g} a(d i)$ which expresses near future and is therefore almost identical to the Dutch light verb, both in form and meaning. Moreover, the Moroccans were slightly more advanced in the use of post-verbal negation than the Turkish learners as well as in the marking of subject-verb agreement. This is an important finding as it presents additional evidence for the relation between syntax and morphology in L2 acquisition. Namely, the fact that the Moroccans were more accurate in the domain of morphology as well as in the syntactic domain when compared to the Turkish learners supports the idea that verbraising is related to agreement marking in L2 acquisition. Such a relation would have been more difficult to maintain if the Moroccan learners had been clearly ahead in morphology but not in syntax.

The differences between the two language groups could be explained in terms of the so-called Alternation Hypothesis (Jansen, Lalleman \& Muysken 1981). This hypothesis holds that Moroccan and Turkish learners of Dutch choose a particular form as their 'default' verb form out of two alternative forms as a function of the basic word order of their L1. More precisely, Moroccan learners are hypothesized to 
look for verbs in sentence-middle position in the $\mathrm{L} 2$ because their native language has SVO/VSO word order. As they focus their attention on the middle part of Dutch sentences, they mainly encounter verb forms ending in -0 and $-t$ (and to a lesser extent -en with plural forms). This explains why they are relatively fast in acquiring subject-verb agreement and concomitantly, verb-raising when compared to Turkish learners. In contrast, Turkish learners of Dutch 'look for' the verb in final position, based on the basic word order of Turkish (SOV). Consequently, these learners mainly attend to infinitives. Since these verbs do not inform them about agreement marking, Turkish learners acquire this phenomenon somewhat later (when compared to Moroccan learners) and consequently, verb-raising is also delayed. Taken together, the results of the study indicate that the native language does not influence the stages that learners with typologically different native languages pass through in acquiring finiteness and negation in Dutch. However, the specific properties of the L1 may come into play in the rate at which learners proceed from one stage to the next.

Max Planck Institute for Psycholinguistics and Vrije Universiteit Amsterdam j.verhagen@let.vu.nl 


\section{References}

Beck, Marie-Luise. 1998. L2 acquisition and obligatory head-movement: Englishspeaking learners of German and the local impairment hypothesis. Studies in Second Language Acquisition 20: 311-348.

Becker, Angelika. 2005. The semantic knowledge base for the acquisition of negation and the acquisition of finiteness. In Henriette Hendriks (ed.), The structure of learner varieties, 263-314. Berlin/New York: Mouton de Gruyter.

Bernini, Giuliano. 2003. The copula in learner Italian: Finiteness and verbal inflection. In Christine Dimroth \& Marianne Starren (eds.), Information structure, linguistic structure, and the dynamics of acquisition, 159-185. Amsterdam: John Benjamins.

Cancino, Herlinda, Ellen Rosansky and John Schuman. 1978. The acquisition of English negatives and interrogatives by native Spanish speakers. In Evelyn Hatch (ed.), Second language acquisition, 207-230. Rowley, MA: Newbury House.

Clahsen, Harald and Martina Penke. 1992. The acquisition of agreement morphology and its syntactic consequences: New evidence on German child language from the Simone-corpus. In Jürgen Meisel (ed.), The acquisition of verb placement, 181-223. Dordrecht: Kluwer.

Clahsen, Harald. 1988. Critical phases of grammar development. A study of the acquisition of negation in children and adults. In Peter Jordens and Josien Lalleman (eds.), Language development, 123-148. Dordrecht: Foris.

Council of Europe. 2001. A common European framework of reference for languages: Learning, teaching, assessment. Cambridge: Cambridge University Press.

Dimroth, Christine. 2005. The finite story. Animated movie developed at the Max Planck Institute for Psycholinguistics, Nijmegen.

Dimroth, Christine, Petra Gretsch, Peter Jordens, Clive Perdue and Marianne Starren. 2003. Finiteness in Germanic languages: A stage-model for first and second language development. In Christine Dimroth and Marianne Starren (eds.), Information structure, linguistic Structure, and the dynamics of acquisition, 65-93. Amsterdam: John Benjamins.

Dimroth, Christine. 2008. Age effects on the process of L2 Acquisition? Evidence from the acquisition of negation and finiteness in L2 German. Language Learning 58: 117-150.

Eubank, Lynn. 1993/94. On the transfer of parametric values in L2 development. Language Acquisition 3: 184-208.

Eubank, Lynn. 1996. Negation in early German-English interlanguage: More valueless features in the L2 initial stage. Second Language Research 12: 73-106. 
Giuliano, Patrizia. 2003. Negation and relational predicates in French and English as second languages. In Christine Dimroth and Marianne Starren (eds.), Information structure, linguistic structure and the dynamics of acquisition, 119-157. Amsterdam: John Benjamins.

Giuliano, Patrizia and Daniel Véronique. 2005. The acquisition of negation in French L2. An analysis of Moroccan Arabic and Spanish 'learner varieties'. In Henriette Hendriks (ed.), The structure of learner varieties, 355-404. Berlin/New York: Mouton de Gruyter.

Haberzettl, Stefanie. 2003. 'Tinkering' with chunks: Form-oriented strategies and idiosyncratic utterance patterns without functional implications in the IL of Turkishspeaking children learning German. In Christine Dimroth and Marianne Starren (eds.), Information structure, linguistic structure and the dynamics of acquisition, 4563. Amsterdam: John Benjamins.

Harrell, Richard. 1962. A short reference grammar of Moroccan Arabic. Washington: Georgetown University Press.

Herschensohn, Julia. 2001. Missing inflection in second language French: Accidental infinitives and other verbal deficits. Second Language Research 17: 273-305.

Ionin, Tania and Ken Wexler. 2002. Why is 'is' easier than '-s'?: Acquisition of tense/agreement morphology by child second language learners of English. Second Language Research 18: 95-136.

Jansen, Bert, Josien Lalleman \& Pieter Muysken. 1981. The alternation hypothesis: Acquisition of Dutch word order by Turkish and Moroccan foreign workers. Language Learning 31: 315-336.

Jordens, Peter (2002). Finiteness in early child Dutch. Linguistics 40: 687-765.

Jordens, Peter and Christine Dimroth. 2006. Finiteness in children and adults learning Dutch. In N. Gagarina \& I. Gülzow (eds.), The acquisition of verbs and their grammar, 173-200. Dordrecht: Springer.

Klein, Wolfgang and Clive Perdue. 1992. Utterance structure: Developing grammars again. Amsterdam: John Benjamins.

Klein, Wolfgang and Clive Perdue. 1997. The basic variety (or: couldn't natural languages be much simpler?). Second Language Research 13: 301-347.

Klein, Wolfgang. 1984. Zweitspracherwerb. Eine Einführung. Königstein: Athenäum.

Klein, Wolfgang. 1994. Time in language. London: Routledge.

Klein, Wolfgang. 1998. Assertion and finiteness. In Norbert Dittmar and Zvi Penner (eds.), Issues in the theory of language acquisition: Essays in honor of Jürgen Weissenborn, 225-245. Bern: Lang. 
Kornfilt, Jaklin. 1997. Turkish. London: Routledge.

Lardiere, Donna. 1998. Dissociating syntax from morphology in a divergent L2 endstate grammar. Second Language Research 14: 359-375.

MacWhinney, Brian. 1991. The CHILDES project: Tools for analyzing talk. Hillsdale, NJ: Lawrence Erlbaum.

Meisel, Jürgen. 1983. Strategies of second language acquisition: More than one kind of simplification. In Roger Andersen (ed.), Pidginization and creolization as language acquisition, 120-157. Rowley, MA: Newbury House.

Meisel, Jürgen. 1997. The acquisition of the syntax of negation in French and German: Contrasting first and second language development. Second Language Research 13: 227-263.

Parodi, Teresa. 1998. Der Erwerb funktionaler Kategorien im Deutschen. Tübingen: Gunter Narr.

Parodi, Teresa. 2000. Finiteness and verb placement in second language acquisition. Second Language Research 16: 355-381.

Poeppel, David and Ken Wexler. 1993. The full competence hypothesis of clause structure in early German. Language 69: 1-33.

Prévost, Philippe and Lydia White. 2000. Missing surface inflection or impairment in second language acquisition? Evidence from tense and agreement. Second Language Research 16: 103-133.

Schumann, John. 1979. The acquisition of English negation by speakers of Spanish: A review of the literature. In Roger Andersen (ed.), The acquisition and use of Spanish and English as first and second languages, 3-32). Washington DC: TESOL.

Starren, Marianne. 2001. The second time. The acquisition of temporality in Dutch and French as a second language. Unpublished doctoral dissertation. University of Tilburg, The Netherlands.

Stauble, Anne-Marie. 1984. A comparison of a Spanish-English and a JapaneseEnglish second language continuum: Negation and verb morphology. In Roger Andersen (ed.), Second languages: A cross-linguistic perspective, 323-353. Rowley, MA: Newbury House.

Vainikka, Anne and Martha Young-Scholten. 1994. Direct access to X'-theory: Evidence from Korean and Turkish adults learning German. In Teun Hoekstra and Bonnie Schwartz (eds.), Language acquisition studies in generative grammar, 265316. Amsterdam: John Benjamins.

Van der Craats, Ineke. to appear. The role of IS in the acquisition of finiteness by adult Turkish learners of Dutch. Studies in Second Language Acquisition, 31. 
Ball story
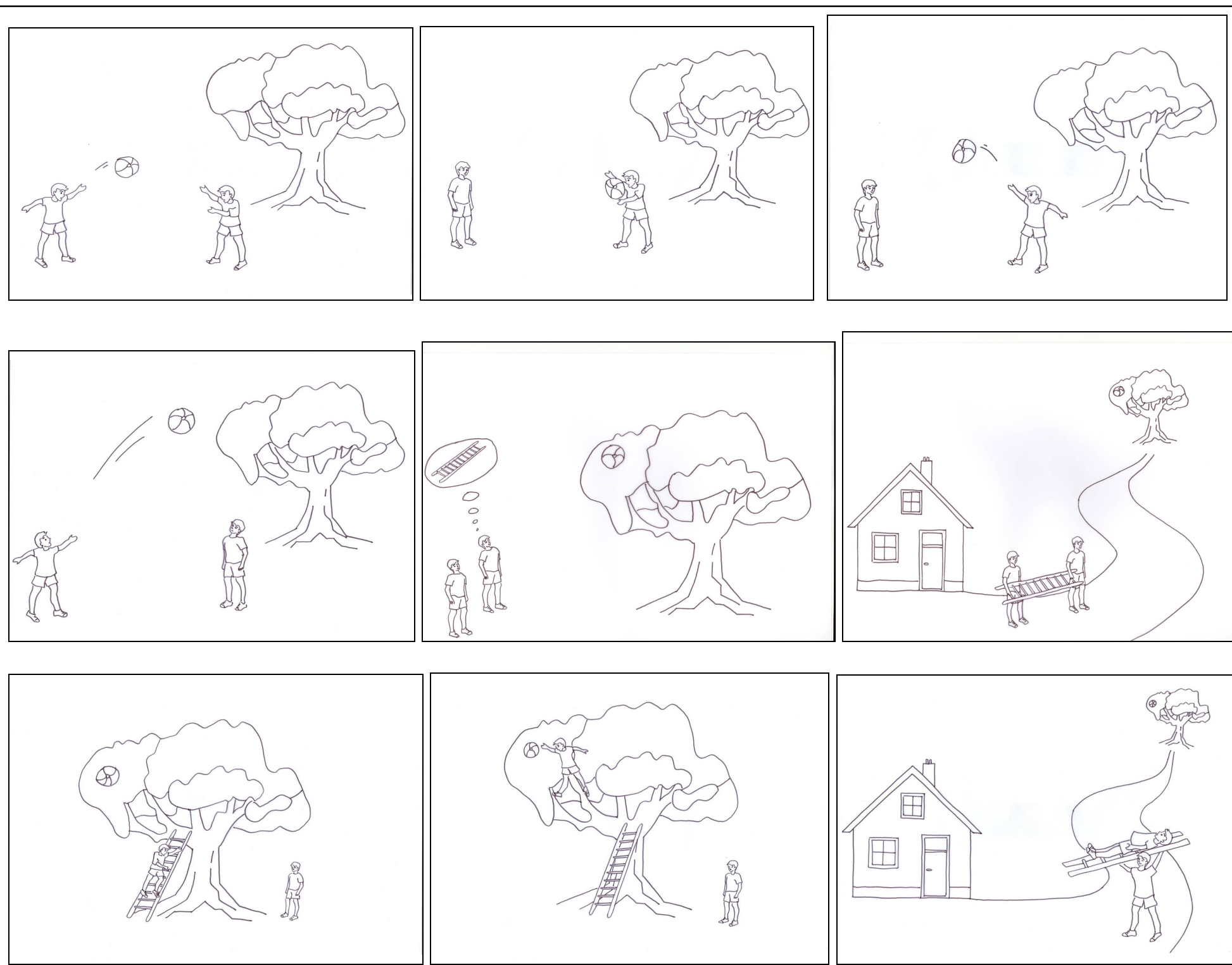
APPENDIX A

Cake story
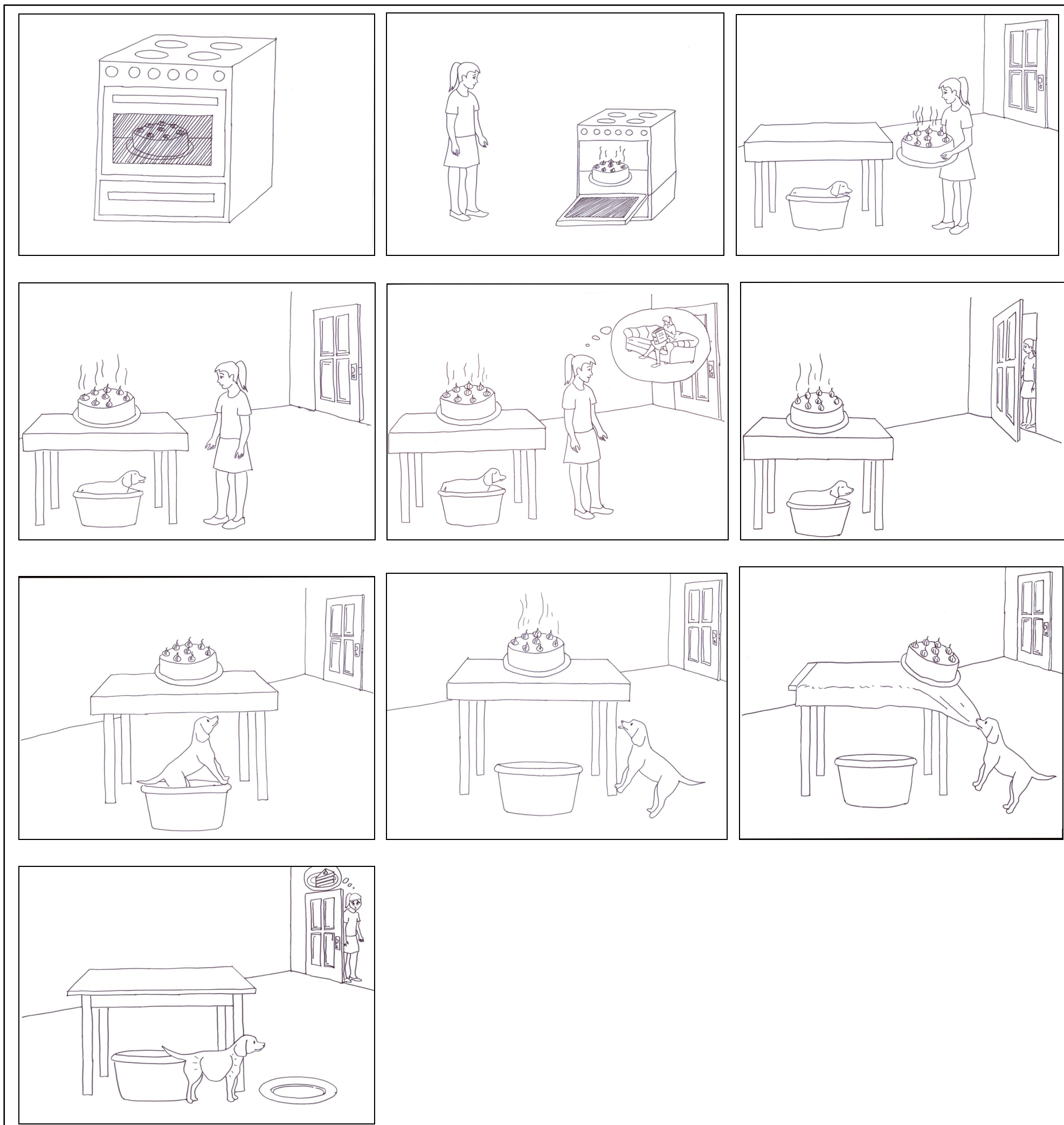